\title{
Raman spectrometry as a screening tool for solvent-extracted azo dyes from polyester-based textile fibres
}

\author{
M.A. Castro ${ }^{\text {a,b }}$, F.J. Pereira ${ }^{\text {a }}$, A.J. Aller ${ }^{\text {a, }}$, D. Littlejohn ${ }^{c}$

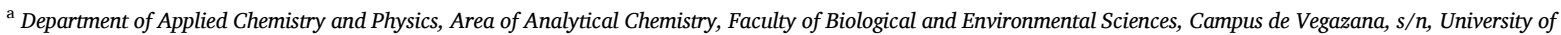 \\ León, E-24071, Leon, Spain \\ ${ }^{\mathrm{b}}$ Department of Mechanical Engineering, Computing and Aerospace, School of Industrial Engineering, Computing and Aerospace, Campus de Vegazana, s/n, University of \\ León, E-24071, Leon, Spain \\ ${ }^{\mathrm{c}}$ WestCHEM/Department of Pure and Applied Chemistry, University of Strathclyde, 295 Cathedral Street, Glasgow, G1 1XL, UK
}

\section{A R T I C L E I N F O}

\section{Keywords:}

Polyester fibres

Textile additives

Azo group

Raman spectrometry

Solvent extraction

Ethanol-diethyl ether

\begin{abstract}
A B S T R A T
Some types of textile fibres are considered to be the cause of allergic reactions and other adverse health effects on humans. The main compounds behind these health problems usually contain azo groups in their chemical structure, which are widely employed as azo dyes in the manufacture of textile and clothing products. In this respect, availability of simple analytical procedures for identifying azo groups in textiles is of concern, not only for toxicological studies, but also for clinical and forensic investigations. In this work, conventional Raman spectrometry was assessed as an analytical tool for identification of the azo function in the extracts of fibres obtained after applying a liquid-solvent extraction procedure to the polyester-based textile products. A mediumpolarity solvent of ethanol-diethyl ether (1:1 mixture) was shown to be the most effective extraction medium. Two laser lines at $514.5 \mathrm{~nm}$ and $785 \mathrm{~nm}$ were compared, with the longer wavelength preferred as additional peaks were identified in the Raman spectrum, which had better signal-to-background and signal-to-noise ratios owing to decreased fluorescence in contrast to excitation at $514.5 \mathrm{~nm}$. The method reported is a convenient procedure that can be applied in many instances when rapid screening of fibre dyes is required.
\end{abstract}

\section{Introduction}

Commercial polyester fibres, based on polyethylene terephthalate (PET), were the first artificial textile fibres manufactured on a large scale by the textile industry. In order to prepare textile fibres with selected special characteristics [1-3], different types of additives have been incorporated in their manufacturing processes [4]. Some of these chemical additives include anti-oxidants, preservatives, metals, and flame-retardants, many of which can cause severe dermatitis and other skin lesions [5]. Other additives involve different types of synthetic dyes, which are generally loosely bound to the fibre surface and, therefore, easily detached to be transferred to the skin [5]. The main organic synthetic dyes are normally grouped as azo, quinacridone, anthraquinone, diketopyrrolopyrrole, or metal-complex dyes, although the azo dyes probably comprise the oldest and largest group. Most polyester fibres show hydrophobic characteristics, lacking ionic properties and so disposed to colour with disperse dyes, which have been linked with many allergic and/or carcinogenic problems [5,6]. Disperse dyes based on azobenzene may feature different functional groups (nitro, amine, hydroxyl, etc.) and are the smallest water-insoluble dyes used for dyeing polyester. Many health problems to humans, including chemical mutagenesis and carcinogenesis $[7,8]$, but particularly those related to acute eczematous reactions, are largely related to the presence of the azo $(-\mathrm{N}=\mathrm{N}-)$ functional group, although potentially also to anthraquinone, indigoid, stilbene, and triphenylmetane chemical derivatives [9]. The adverse effects encountered can vary with the country involved, patient type, and dye class. However, the most common health problems concerning disperse dyes are dye dermatitis, followed by toxicological and respiratory effects [10]. Also, the presence of synthetic azo dyes on polyester fibres, especially benzidine-based azo dyes containing aromatic amines, is considered key factor in the genesis and development of different types of cancers [6]. In this respect, azo dyes based on benzidine have been classified as category 2 carcinogens. More than 3000 individual azo dyes are currently in use, representing about $60 \%$ of the total organic dyes, which usually show long degradation half-lives and low lethal concentration values ( $\left.\mathrm{LD}_{50}\right)$ [11].

\footnotetext{
* Corresponding author.

E-mail addresses: aj.aller@unileon.es, ajallf@unileon.es (A.J. Aller).
} 
Consequently, reduction in the use of textile azo dyes is a priority issue of preventive action in medicinal and occupational health $[12,13]$. It is also known that degradation products of textile dyes prevalent in wastewater systems are highly toxic to humans, generating a serious environmental problem [13]. For this reason, evaluation of the environmental and toxicological impact of the azo colorants is of the greatest concern.

Various analytical techniques have been used to characterise and/or identify functional groups and particularly the azo group [14] in dye molecules. In general, analytical approaches include an extraction stage using low polarity solvents, such as chlorobenzene, methanol, dimethylsulfooxide, acetonitrile and dimethylformamide [15,16]. HPLC has been widely deployed for molecular separation, particularly with UV-Vis or fluorescence detection systems [4,17], due to the abundant chromophores usually present in the azo pigments, although hyphenated mass spectrometry detectors have also been used [15,18-20]. Minimally invasive analyses with vibrational spectroscopy techniques such as Raman scattering have been reported [21-25], including applications in the field of modern art [21,25,26]. Raman spectrometry is particularly informative about the polarizable groups, such as the azo group, which contains a low energy state, where the electronic transitions $\pi \rightarrow \pi^{*}$ are highly favourable. Furthermore, Raman spectrometry is also one of the most versatile analytical tools for a direct spectroscopic characterisation of natural samples, even those containing high levels of water. However, as conventional Raman spectrometry is not an especially sensitive technique [27], different modalities with enhanced detection capabilities have been assessed for characterisation of synthetic azo pigments [22-24] especially surface-enhanced Raman spectrometry, although calibration and operational problems, amongst other weaknesses, have limited its success in routine analysis. The identification of a single azo pigment in complex matrices, like textile fibres, can prove challenging owing to the low concentration levels, variability of the chemical structures encountered, low spectral intensity and possible overlapping of the Raman bands, as well as generation of a super-imposed intense fluorescence spectrum [4,28]. Additional identification problems of a single pigment type might also arise because the Raman spectra are sensitive to changes to the chemical environment of the $\mathrm{N}=\mathrm{N}$ group. If these issues can be overcome, a simple procedure to screen samples and provide evidence of the presence of a potentially dangerous azo group would be useful for toxicological and forensic purposes. The first tentative aim of this work was to use conventional Raman spectrometry for a direct, in situ screening of the azo group on the polyester-based textile fibres. However, the complex fibre matrix produces strong fluorescence obscuring many Raman peaks. Consequently, an alternative procedure was devised based on the analysis of dye extracts by conventional Raman spectrometry. Different solvent mixtures were assessed and the best results were obtained with a mixture of ethanol and diethyl ether, which has not previously been reported as an extraction medium for medium-polarity azo dyes on polyesters fibres. Other studies have used more polar/toxic and/or complex mixtures of extractants [14]. The potential advantages of the reported analytical approach include the simplicity and rapid procedure of the extraction stage, the use of less toxic solvents, and only minimal amounts of both sample and extractant. The advantages of the method make it attractive for screening textile fibres for the presence of an azo group prior to more detailed examination.

\section{Experimental}

\subsection{Instruments and operating conditions}

The Raman spectra were obtained using a Renishaw Ramanscope spectrometer (Renishaw, London, UK) fitted with a CCD detector and an Olympus optical microscope model BH2-UMA, objective 50X and automatic focal positioning. The Raman spectrometer was calibrated using a multi-wavelength source. Raman spectrometry measurements were performed at room temperature using the excitation lines at 514.5 $\mathrm{nm}$ and $785 \mathrm{~nm}$ of an argon ion laser and a diode laser, respectively, at a nominal power level of $100 \%$ equating to $\sim 5 \mathrm{~mW}$ at the sample; in some instances, the power had to be reduced due to saturation of the detector. The experimental conditions were $10 \mathrm{~s}$ accumulation time, $1 \mathrm{~min}$ acquisition time, an X20 objective and a scan range of $200-4500 \mathrm{~cm}^{-1}$. The Raman spectra were obtained using a gold thin-film as a sample support, where $50 \mu \mathrm{L}$ of the extract is deposited and dried for the analysis. The average of 100 replicates measurements was used in all experiments. The Raman spectra were processed using Origin 9.0 software (OriginLab Corporation, Northampton, MA, USA). A Bransonic sonicator, model B-5 (Soest, The Netherlands) was also used for facilitating the extraction of the azo dyes.

\subsection{Samples and chemicals}

Samples of the polyester textile fibres from five jeans, differing in colour (green, black, white, blue, and brown), usually dyed with disperse dyes, were collected from the same manufacturer and evaluated by conventional Raman spectrometry. All chemicals (ethanol, diethyl ether, ethyl acetate and carbon tetrachloride) used in this study were of analytical reagent grade (Merck, Darmstadt, Germany).

\subsection{Extraction procedure}

Direct analysis of fibres by conventional Raman spectrometry proved inadequate owing to the occurrence of intense molecular fluorescence, with only the peaks from the base fibre material noted in the Raman spectra. Consequently, the azo dyes were extracted by treating small pieces $\left(\sim 4 \mathrm{~cm}^{2}\right)$ of the original washed textile fibres with $10 \mathrm{~mL}$ of the following organic solvents: ethanol-diethyl ether (1:1), ethyl acetate, or carbon tetrachloride for $24 \mathrm{~h}$ contact time at $50{ }^{\circ} \mathrm{C}$. Using a sonicator to aid extraction reduces the contact time to $1 \mathrm{~h}$.

From a QA/QC perspective, we assured analytical quality of the solvent extraction and analysis stages working with SI units, and assuring the uncertainty for each step. In this way, the developed approach fits for the pursued purpose. Furthermore, important analytical parameters, such as reproducibility and specificity, were stated, performing all analytical measurements in triplicate, using standard compounds of analytical reagent grade and comparing all experimental data with blank analysis.

\section{Results and discussion}

All Raman spectra recorded in this work were acquired using excitation laser lines at $514.5 \mathrm{~nm}$ or $785 \mathrm{~nm}$. In general, the Raman spectra of the same sample type show no strong differences between both excitation lines, although the spectrum produced with the $785 \mathrm{~nm}$ line usually revealed some extra and well-differentiated Raman shifts, probably because fluorescence was less intense at the longer wavelength, improving the signal-to-background ratio. The impact of fluorescence was reduced by plotting first and/or second derivative Raman spectra (Fig. SI-1). The Raman spectra (Figs. SI-2A, SI-2B, Tables SI-1) of the original textile fibres, comprised mainly peaks of PET (polyester component) with no obvious contributions to the spectra from the azo dyes (see Supplementary Material).

In order to extract and potentially concentrate the azo dyes, the PET fibres were treated separately with three organic solvents differing in polarity and dielectric constant (Tables SI-2): ethanol-diethyl ether (1:1), ethyl acetate, or carbon tetrachloride. The Raman spectra of the ethanol-diethyl ether (1:1) extracts (Fig. 1A, 1B, 1C, Table 1) show many useful Raman shifts, particularly using the excitation laser line at 785 nm.

Ethyl acetate (Fig. SI-3) and carbon tetrachloride (Fig. SI-4) were less efficient extractants: the Raman spectra were dominated by characteristics of the solvent molecules, such as the peaks caused by $\mathrm{CH}$ 

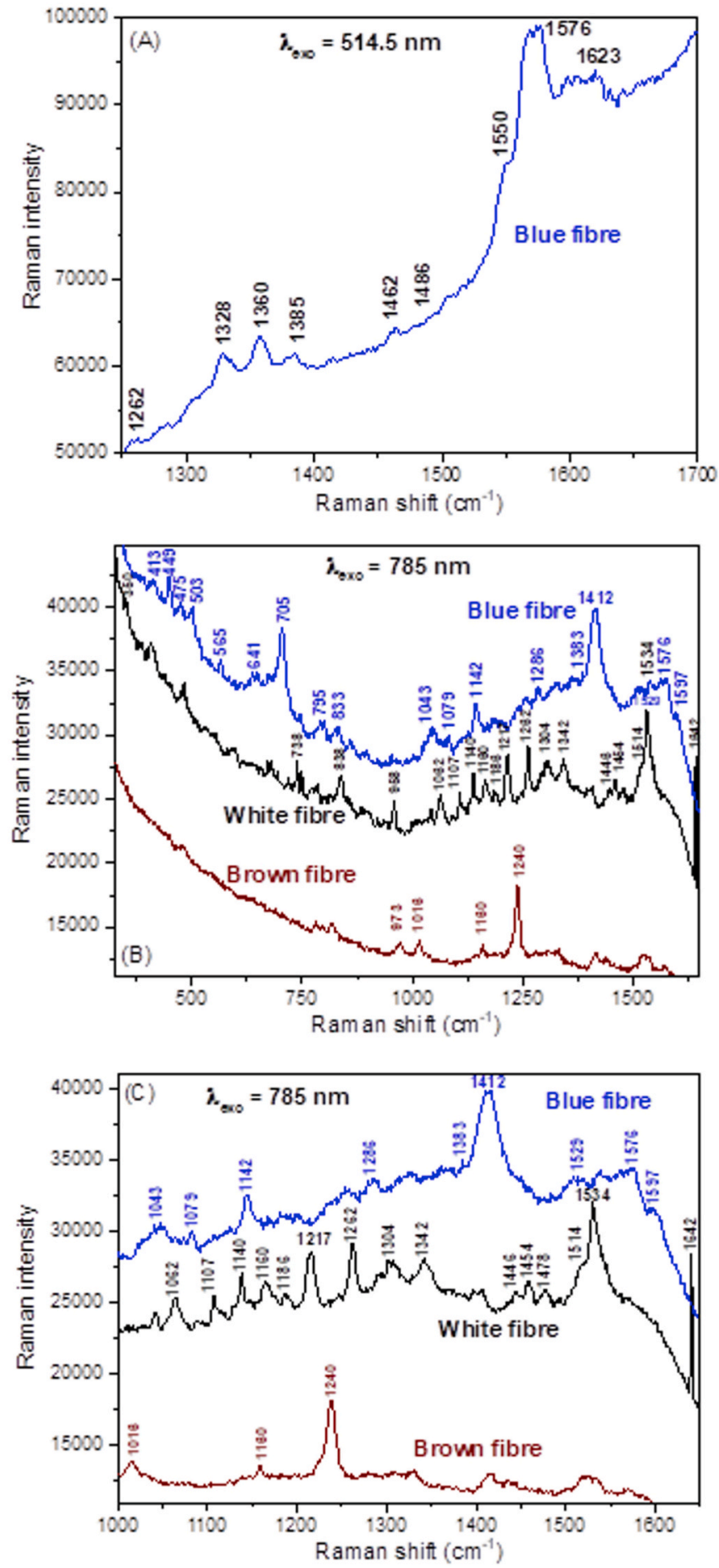

Fig. 1. Raman spectra of the ethanol-diethyl ether (1:1) extract (A, B, C), using two excitation laser lines at $514.5 \mathrm{~nm}(\mathrm{~A})$ and at $785 \mathrm{~nm}(\mathrm{~B}, \mathrm{C})$. Picture (C) represents shortened Raman spectra from (B), for a better visualization of the most important Raman shifts of the azo group. Extraction was at $50{ }^{\circ} \mathrm{C}$ and for $24 \mathrm{~h}$.

deformations and the intra-molecularly $\mathrm{H}$-bonded ester $\mathrm{C}=\mathrm{O}$ group, but did not contain peaks from the azo group. These results confirm that in the extraction procedure, not only the dipole moment of the solvent takes some effect, but also, and probably more important, the dielectric constant (Tables SI-2). It is known that solvents with high dielectric constants facilitate dissolution of polar or charged molecules, while dipole moment stabilizes solvent-solute orientation. However, disperse
Table 1

Tentative assignments of the main Raman bands for the ethanol-diethyl ether $(1: 1)$ extract. The arrow means increased $(\uparrow)$ and decreased $(\downarrow)$ intensity of the peaks.

\begin{tabular}{|c|c|c|c|}
\hline $\begin{array}{l}514 \\
\mathrm{~nm}\end{array}$ & $785 \mathrm{~nm}$ & Assignment & $\begin{array}{l}\text { Jean } \\
\text { colour }\end{array}$ \\
\hline \multirow[t]{2}{*}{$1623 \downarrow$} & 1642 & $\begin{array}{l}\text { Amide I; } v_{s}(\mathrm{C}=\mathrm{O} \text {, ring } \mathrm{C}=\mathrm{C}) \\
\text { Azomethine } v_{\mathrm{s}}(\mathrm{C}=\mathrm{N})\end{array}$ & White \\
\hline & 1597 & $\begin{array}{l}\nu_{\text {as }}\left(-\mathrm{NO}_{2}\right) ; \text { Azomethine } \nu_{\mathrm{s}}(\mathrm{C}=\mathrm{N}) ; \\
\text { Diarylide and bisacetoacetarylide }\end{array}$ & Blue \\
\hline \multirow[t]{3}{*}{1576} & 1576 & $\nu_{\mathrm{s}}(\mathrm{N}=\mathrm{N})(E)$-azo; Azomethane & Blue \\
\hline & $1534 \uparrow$ & Azo-benzyl & White \\
\hline & $1514 \downarrow$ & $\begin{array}{l}(Z) \text {-azo; } \delta_{\mathrm{s}}(\mathrm{OH}) \text { in-plane; } \delta(\mathrm{NH}) ; \nu_{\mathrm{s}}(- \\
\mathrm{N}=\mathrm{N}-) \text { in } Z \text {-azobenzene }\end{array}$ & White \\
\hline $1486 \downarrow$ & 1478 & CC stretching vibrations & $\begin{array}{l}\text { Blue, } \\
\text { White }\end{array}$ \\
\hline \multirow[t]{3}{*}{$1462 \downarrow$} & 1454 & $\begin{array}{l}\nu_{\mathrm{s}}(\mathrm{N}=\mathrm{N})(E) \text {-azo; Azobenzene ring } \\
\text { vibrations }\end{array}$ & $\begin{array}{l}\text { Blue, } \\
\text { White }\end{array}$ \\
\hline & $1446 \downarrow$ & $\begin{array}{l}\nu_{\mathrm{s}}(\mathrm{N}=\mathrm{N})(E) \text {-azo (ring vibration); } \delta \mathrm{s} \\
(\mathrm{N}=\mathrm{N}) \text { phenyl ring }\end{array}$ & White \\
\hline & $1412 \uparrow$ & (E)-azobenzene (aromatic substitution) & Blue \\
\hline $1385 \downarrow$ & $1383 \downarrow$ & $\nu_{\mathrm{s}}(-\mathrm{N}=\mathrm{N}-) ; \delta_{\mathrm{s}}\left(\mathrm{CH}_{3}\right)$ & Blue \\
\hline 1360 & & Naphthol AS; Naphtalene ring & Blue \\
\hline \multirow[t]{3}{*}{1328} & 1342 & $\begin{array}{l}\nu_{\mathrm{s}}\left(-\mathrm{NO}_{2}, \mathrm{C}-\mathrm{CH}_{3}\right) ; \nu(-\mathrm{C}-\mathrm{N}=\mathrm{N}-\mathrm{C}-) ; \\
\nu_{\mathrm{s}}\left(\mathrm{COO}^{-}\right) ; \text {Acetoacetic arylides; Benzyl } \\
\text { amide; Naphthalene bands }\end{array}$ & White \\
\hline & 1304 & $\omega\left(\mathrm{CH}_{2}\right), \delta(\mathrm{HCC}), \delta(\mathrm{HCO}), \delta(\mathrm{COH})$ & White \\
\hline & 1286 & $\begin{array}{l}\nu(\mathrm{C}-\mathrm{N}) \text {; Diarylide dyes (C-C bridge in a } \\
\text { biphenyl moiety); Naphthol AS; Disazo } \\
\text { pyrazolone, Bisacetoacetarylide }\end{array}$ & Blue \\
\hline \multirow[t]{20}{*}{$1262 \downarrow$} & $1262 \uparrow$ & $\nu(\mathrm{C}-\mathrm{N})$ planar azo dyes & White \\
\hline & $1240 \uparrow$ & Amide III; phenyl-N & Brown \\
\hline & $1217 \uparrow$ & Sulfonic acid; $\nu_{\mathrm{as}}(\mathrm{C}-\mathrm{N})$ azo & White \\
\hline & 1160-1186 & $\begin{array}{l}\nu_{\mathrm{s}}(\mathrm{C}-\mathrm{N} \text { azo }) \text { (probably from acetoacetic } \\
\text { arylide lake pigments); } \nu_{\mathrm{s}}\left(\mathrm{SO}_{2}\right) ; \text { phenyl- } \mathrm{N}\end{array}$ & White \\
\hline & $1140-1142 \uparrow$ & $\delta_{\mathrm{s}}(\mathrm{C}-\mathrm{N}$ azo $)$ & $\begin{array}{l}\text { White, } \\
\text { Blue }\end{array}$ \\
\hline & 1107 & $\nu(\mathrm{COH}), \nu_{\mathrm{a}}(\mathrm{C}-\mathrm{O}-\mathrm{C})$; glyc ring breath & White \\
\hline & 1079 & Sulfone, Sulphonamide & \\
\hline & $\begin{array}{l}1062-1043- \\
1016 \text { sh }\end{array}$ & $\begin{array}{l}\mathrm{R}-(\mathrm{S}=\mathrm{O})-\mathrm{R} ; v_{\mathrm{s}}\left(\mathrm{SO}_{3}^{-}\right) ; o \text {-disubstituted } \\
\text { benzene rings; } v_{\mathrm{as}}(\mathrm{N}=\mathrm{N}) \text { heterocyclic }\end{array}$ & $\begin{array}{l}\text { White, } \\
\text { Blue }\end{array}$ \\
\hline & 973,958 & $\mathrm{C}-\mathrm{C}-\mathrm{O}$ out of phase; Benzylamide & $\begin{array}{l}\text { Brown, } \\
\text { White }\end{array}$ \\
\hline & $833-838$ & $\mathrm{C}-\mathrm{O}-\mathrm{C}$ & $\begin{array}{l}\text { Blue, } \\
\text { White }\end{array}$ \\
\hline & 795 & $\mathrm{C}-\mathrm{C}-\mathrm{O}$ in phase & Blue \\
\hline & 738 & $\nu_{\mathrm{s}}(\mathrm{C}-\mathrm{S})$ & White \\
\hline & $705 \uparrow$ & $\mathrm{C}-\mathrm{C}_{4}$ & Blue \\
\hline & 641 & $v_{\mathrm{s}}(\mathrm{C}=\mathrm{S})$ & Blue \\
\hline & 565 & $\mathrm{C}-\mathrm{Cl}$ & Blue \\
\hline & 503 & $\nu(\mathrm{S}-\mathrm{S})[g-g-g] ; \nu_{\mathrm{s}}(\mathrm{C}-\mathrm{S})\{g:$ gauch $\} ; \mathrm{Si}-\mathrm{O}-\mathrm{Si}$ & Blue \\
\hline & 475 & $\nu_{\mathrm{s}}(\mathrm{S}-\mathrm{S})$ & White \\
\hline & 449 & $v_{\mathrm{s}}(\mathrm{S}-\mathrm{S})$ & Blue \\
\hline & 413 & S-S; M - O (M: metal) & $\begin{array}{l}\text { White, } \\
\text { Blue }\end{array}$ \\
\hline & 350 & BON dyes & White \\
\hline
\end{tabular}

dyes, the main dyes used for dyeing polyester fibres, show very low solubility in polar solvents, such as water. Accordingly, the electrostatic factor (product between dielectric constant and dipole moment) is taken as an indicator of the solvent power. Ethanol shows an electrostatic factor at least five times higher than the other selected solvents, thus facilitating extraction/solubilisation. In the dyeing process, dyes are retained by solid-solid interactions, where H-bridges and van der Waals forces, but not chemical bonds, are prevalent. Therefore, since the chemical structure of the disperse dyes involves small, planar and nonionic monoazo molecules, with some attached functional groups, solubilisation of disperse dyes depends on the number and type of the functional groups present in the molecule, slightly modified by the aromatic rings. In many cases, solubilisation is incomplete and a suspension is formed. Thus, the most probably solubilisation process by the ethanol-diethyl ether mixture involves physical interaction of the solvent molecules with the surface of the dye particle, a process which is facilitated by the use of ultrasound irradiation, thereby reducing the 
extraction time.

Unfortunately, irrespective of the extractant used, fluorescence prevented Raman analysis of green and black jean fibres even with excitation at $785 \mathrm{~nm}$. This problem comes from the presence in the extract of strong fluorescent compounds, mainly other than azo dyes [4]. For the other fibre types, a powerful indication of the presence of an azo moiety is provided from the Raman spectra of the ethanol-diethyl ether (1:1) extract, which show a band at $1383-1385 \mathrm{~cm}^{-1}$ (Fig. 1A), ascribed to the symmetrical stretching mode of the azo $(-\mathrm{N}=\mathrm{N}-)$ group [25]. Most synthetic azo dyes have an $(E)-\mathrm{N}=\mathrm{N}-$ group with a hydroxyl or keto function at the $\beta$-position. The $\mathrm{N}=\mathrm{N}$ stretching vibrations of symmetrically substituted (E)-azo dyes give rise to strong Raman bands in the range $1400-1580 \mathrm{~cm}^{-1}$. The peak at $1576 \mathrm{~cm}^{-1}$ and the shoulder at $1550 \mathrm{~cm}^{-1}$ (Fig. 1A, 1B, 1C) are assigned to $v_{(\mathrm{N}}={ }_{\mathrm{N})}$ (azobenzene) with aliphatic substituent, while the $\mathrm{N}=\mathrm{N}$ valence mode of $(E)$-azobenzene with aromatic substitution accounts for the peak at $1412 \mathrm{~cm}^{-1}$ (usually in the range 1405-1450 $\mathrm{cm}^{-1}$ ) (Fig. 1B and C, blue fibre). Also, the Raman mode of (Z)-azobenzene appears as a shoulder around 1514 $\mathrm{cm}^{-1}$ (Fig. 1B and C, white fibre), although minor evidence of the (Z)-azo linkage was noted in this study (Fig. 1B and C). The Raman band at $1454-1462 \mathrm{~cm}^{-1}$ (Fig. 1A) is indication of an azobenzene ring vibration, but it suffers some overlap with the peak arising from $\mathrm{CH}$ bending or scissoring. The Raman shift at $1446 \mathrm{~cm}^{-1}$ can be due to $\mathrm{N}=\mathrm{N}$ stretch vibrations coupled with ring vibrations. As expected, the C-N (azo) symmetric stretching mode appears in the region $1160-1186 \mathrm{~cm}^{-1}$ (Figs. 1B, 1C, SI-4) for the acetoacetic arylide lake pigments, largely shifted from the medium intensity peak at $1140 / 1142 \mathrm{~cm}^{-1}$ (Fig. $1 \mathrm{~B}$ and C). Other characteristic peaks for acetoacetic arylides appear at 1328 $\mathrm{cm}^{-1}$ (Figs. 1A), $1342 \mathrm{~cm}^{-1}$ (Fig. $1 \mathrm{~B}$ and C) (aromatic nitro group vibration) and $958 \mathrm{~cm}^{-1}$ (Fig. 1B and C) (benzylamide). From the above results, we can state that the main dye category found in the ethanol-diethyl ether (1:1) extract was azobenzene (disperse dyes).

Notwithstanding, there are difficulties in the assignments and analysis of the Raman spectra of the azo compounds, due to a tautomerization reaction with the formation of hydrazone tautomers (hydroxylazo/keto-hydrazone equilibrium): $\quad-\mathrm{N}=\mathrm{N}-\mathrm{C}=\mathrm{C}-\mathrm{OH} \leftrightarrow$ $-\mathrm{HN}-\mathrm{N}=\mathrm{C}-\mathrm{C}=\mathrm{O}$. The stretching vibrations of the hydrazone $(\mathrm{C}=\mathrm{N}$ plus $\mathrm{C}=\mathrm{O}$ ) forms show Raman peaks around $1623 \mathrm{~cm}^{-1}$ (Fig. 1A), usually at $1642 \mathrm{~cm}^{-1}$ (Fig. 1B and C), and typically in the range $1630-1690 \mathrm{~cm}^{-1}$. Formation of a hydrazo structure might be indicated though two Raman bands at $\sim 1605 \mathrm{~cm}^{-1}(-\mathrm{C}=\mathrm{N}-)$ ) and $\sim 1380 \mathrm{~cm}^{-1}(\mathrm{~N}=\mathrm{N})$ [29], but this did not occur for the moderate polarity solvent mixture used (ethanol-diethyl ether), suggesting shortage of crystallization/aggregation, electron-withdrawing $p$-substituents (such as $-\mathrm{COOH},-\mathrm{COOR},-\mathrm{CHO}$, $\left.-\mathrm{CN},-\mathrm{SO}_{3} \mathrm{H},-\mathrm{X}\right)$ and large aromatic systems.

In this work, only minor photoisomerization occurs when exciting at $514 \mathrm{~nm}$ (Fig. 1A, blue fibre at $1623 \mathrm{~cm}^{-1}$ ) and $785 \mathrm{~nm}$ (Fig. 1B and C, white fibre at $1642 \mathrm{~cm}^{-1}$ ). This would be a clear consequence of instability of the (Z)-hydroxyazo form, which usually reverts spontaneously to the (E)-form. Trans-(E)-azobenzene is the most stable thermodynamic form and adopts a planar geometry, while the aromatic rings on the cis(Z)-form are skewed out of plane. The mechanism of isomerization still remains a subject of controversy mainly linked to the $\mathrm{N}$ lone pair in the azo group. Two routes of isomerization are described the most likely: (i) rotation (torsion or twist) about the central $\mathrm{N}=\mathrm{N}$ bond which included a $\pi$ bond rupture, and (ii) inversion $\{$ in plane lateral shift $\}$ through a linear transition state where the $\pi$ bond remains intact. Planar azo dyes, such as the trans-(E)-form, show a maximum $\pi$-electron density on the central $\mathrm{N}=\mathrm{N}$ bond with a strong double bond character for $\mathrm{N}=\mathrm{N}$, a bond order closely to 2 and an obvious decreased $\pi$-conjugation. As a result, the main azo stretching vibration, $\nu_{(\mathrm{N}}=_{\mathrm{N})}$, of planar azo dyes appears at higher frequency $\left(1462 \mathrm{~cm}^{-1}\right.$ ) (Fig. 1A). However, a reverse trend is observed for the $\mathrm{C}-\mathrm{N}$ stretching vibration. Thus, the $\mathrm{C}-\mathrm{N}$ bond in planar azo dyes exhibits more single bond character and consequently $\nu_{(\mathrm{C}-\mathrm{N})}$ appears at lower wavenumbers $\left(\sim 1262 \mathrm{~cm}^{-1}\right)$ [30] (Fig. 1A blue fibre, $1 \mathrm{~B}, 1 \mathrm{C}$ white fibre). According to the relative intensity of the two mentioned above peaks, the blue fibre would show an equivalent extension of the double $\mathrm{N}=\mathrm{N}$ and single $\mathrm{C}-\mathrm{N}$ bonds (Fig. 1A, 1B, 1C), while the white fibre would show a larger extension of the single $\mathrm{C}-\mathrm{N}$ bond (Fig. 1B). These results agree with the presence of azo-benzyl groups, which give rise to a clearly identifiable feature at $1534 \mathrm{~cm}^{-1}$ (Fig. 1B and $\mathrm{C}$ white fibre).

Some azo dyes can also incorporate amide $\left(-\mathrm{CONH}_{2}\right)$, nitro $\left(-\mathrm{NO}_{2}\right)$, amine $\left(-\mathrm{NH}_{2}\right)$, hydroxyl $(-\mathrm{OH})$ and sulfonate $\left(-\mathrm{SO}_{3}^{-}\right)$groups, among others. However, we only found the possible presence of electronwithdrawing substituents. The amide I and amide III bands in the Raman spectra appear around 1620-1642 $\mathrm{cm}^{-1}$ (bathochromic shift from $\sim 1670 \mathrm{~cm}^{-1}$ ) and at $1262 \mathrm{~cm}^{-1}$ (hypsochromic shifts from $\sim 1240$ $\mathrm{cm}^{-1}$ for $\beta$-sheet and random coil secondary structures) [31] (Fig. 1A, 1B, 1C), respectively, which overlap with some azo bands. The Raman peak at $1160 \mathrm{~cm}^{-1}$, used to diagnose the presence of sulfone groups $\left(>\mathrm{SO}_{2}\right.$ symmetric stretch) (Figs. 1B, 1C, SI-3), allows differentiation between lake and non-lake dyes, although it overlaps with the C-N (azo) symmetric stretching. Nonetheless, the relatively strong peak at $1160 \mathrm{~cm}^{-1}$ suggests the presence of a less-polar azo dye, rather than the polar sulfonate group. The stretch vibration of the sulfinyl $(S=0)$ functional group in sulfoxides $(\mathrm{R}-\mathrm{S}(=\mathrm{O})-\mathrm{R})$ appears in the range $1020-1070 \mathrm{~cm}^{-1}$ (Fig. 1B and C).

The shoulder at $1597 \mathrm{~cm}^{-1}$ (Fig. SI-2B, 2C) relates to $\nu_{\mathrm{as}}\left(\mathrm{NO}_{2}\right)$, correlating with Disperse Blue 79:1 [17], because this dye contains several nitro groups in its chemical structure. However, caution is required in assigning the feature to the entire molecule. The Raman band at $1576 \mathrm{~cm}^{-1}$ (Fig. 1B and C, blue fibre), which ascribes to the $-\mathrm{N}=\mathrm{N}-(E)-\mathrm{azo}$, correlates with the naphthol AS dye [25], although this dye is largely used for dying cotton and not so much for PET. Raman features of an aromatic carboxylate group Ar-COO ${ }^{-}, \nu_{\mathrm{s}}\left(\mathrm{CO}_{2}\right)$, typically present in azo BONA pigment lakes, appear in the range 1360-1450 $\mathrm{cm}^{-1}$, overlapping the band of $v(\mathrm{~N}=\mathrm{N})$. A typical feature for the diarylide dyes is the band at $1286 \mathrm{~cm}^{-1}$ (Fig. $1 \mathrm{~B}$ and $\mathrm{C}$, blue fibre), which correlates with the bridging bond between two benzene functions. $\boldsymbol{\beta}$-Naphthol dyes are azo compounds without amide and sulfonic groups. The presence of BON ( $\beta$-oxynaphthoic acid) dyes has been suggested by the existence of the $\mathrm{O}-\mathrm{C}-\mathrm{C}$ bending band at $350 \mathrm{~cm}^{-1}$ (Fig. 1B and $\mathrm{C}$, white fibre). In the low wavenumber region, typical peaks lying with the skeletal vibrations from CCC and COC ring deformations can be found (Fig. 1B and Table S1), together with peaks ascribed to disulphides (S-S) and sulphide (C-S) stretching vibrations, particularly involved in structural conformation [32-35]. For a better identification of the Raman shift related to each fibre colour, these shifts were written in bold and the name of the jean colour included in the four column of Table S1.

\section{Conclusions}

Raman spectrometry was used successfully for accurate identification of the azo group in dyes extracted from PET fibres with an ethanoldiethyl ether (1:1) mixture. Comparisons with other solvents confirmed that extraction procedures using solvents with medium-polarity and relatively high dielectric constants show high efficiency and reliability in the extraction of the medium-polarity azo dyes from the polyesterbased textile fibres. The most abundant dyes extracted were azobenzene disperse dyes, from which the (E)-azo isomers (thermodynamically more stable) were the predominant forms. The method developed allowed differences between coloured textile fibres to be discerned and so is a useful procedure for screening of dyes on fibres prior to more detailed analysis. The Raman peaks did not suffer bathochromic (Stokes) shifts using the excitation laser line at $785 \mathrm{~nm}$, as compared with the $514.5 \mathrm{~nm}$ line, for any of the dye extracts analysed. According to the number and better signal-to-noise ratio of the Raman peaks found, the most appropriate excitation source was the $785 \mathrm{~nm}$ laser line. Fluorescence and the poor sensitivity of conventional Raman spectrometry are main limitations of this technique. Nonetheless, 
fluorescence can be avoided incorporating mitigating instrumental technologies such as time-gating. In the same way, sensitivity limitations can be partly overcome by combining efficiently a suitable size of sample fibre, a small extractant volume and a large volume sampled for analysis. It should be noted that polar azo compounds would not ordinarily be extracted with this solvent mixture. Potential quantitative analysis by conventional Raman spectrometry would require additional studies, including improvements in current calibration procedures and the use of certified reference textile materials, non-existent at this time. Furthermore, due to the poor intrinsic sensitivity of this spectrometric technique, careful selection of the wavenumber range is required for quantitative analysis, although several peaks could be chosen.

\section{CRediT authorship contribution statement}

M.A. Castro: Investigation, All authors discussed the results and reviewed the manuscript. F.J. Pereira: Investigation, All authors discussed the results and reviewed the manuscript. A.J. Aller: Conceptualization, Writing - original draft, All authors discussed the results and reviewed the manuscript. D. Littlejohn: Writing - review \& editing, All authors discussed the results and reviewed the manuscript.

\section{Declaration of competing interest}

The authors declare that they have no known competing financial interests or personal relationships that could have appeared to influence the work reported in this paper.

\section{Appendix A. Supplementary data}

Supplementary data to this article can be found online at https://doi. org/10.1016/j.polymertesting.2020.106765.

\section{References}

[1] P. Savarino, S. Parlati, R. Buscaino, P. Piccinini, I. Degani, E. Barni, Effects of additives on the dyeing of polyamide fibres. Part I: $\beta$-cyclodextrin, Dyes Pigments 60 (2004) 223-232, https://doi.org/10.1016/S0143-7208(03)00142-6.

[2] P. Savarino, S. Parlati, R. Buscaino, P. Piccinini, C. Barolo, E. Montoneri, Effects of additives on the dyeing of polyamide fibres. Part II: methyl- $\beta$-cyclodextrin, Dyes Pigments 69 (2006) 7-12, https://doi.org/10.1016/j.dyepig.2005.02.003.

[3] J. Broda, A. Gawlowski, C. Slusarczyk, A. Wlochowicz, J. Fabia, The influence of additives on the structure of polypropylene fibres, Dyes Pigments 74 (2007) 508-511, https://doi.org/10.1016/j.dyepig.2006.10.004.

[4] J.C. Feo, A.J. Aller, Spectrometric identification of solvent extractable organic additives in polyester-based textile fibers, Fibers Polym. 12 (2011) 594-601, https://doi.org/10.1007/s12221-011-0594-2.

[5] M. Pratt, V. Taraska, Disperse blue dyes 106 and 124 are common causes of textile dermatitis and should serve as screening allergens for this condition, Am. J. Contact Dermatitis 11 (2000) 30-41, https://doi.org/10.1016/S1046-199X(00) 90030-7.

[6] K. Golka, S. Kopps, Z.W. Myslak, Carcinogenicity of azo colorants: influence of solubility and bioavailability, Toxicol. Lett. 151 (2004) 203-210, https://doi.org/ 10.1016/j.toxlet.2003.11.016.

[7] J. Khatri, P.V. Nidheesh, T.A. Singh, M.S. Kumar, Advanced oxidation processes based on zero-valent aluminium for treating textile wastewater, Chem. Eng. J. 348 (2018) 67-73, https://doi.org/10.1016/j.cej.2018.04.074.

[8] King-Thom Chung, Azo dyes and human health: a review, J. Environ. Sci. Health, Part C 34 (2016) 233-261, https://doi.org/10.1080/10590501.2016.1236602.

[9] Ch-J. Le Coz, Clothing, in: J.D. Johansen, P.J. Frosch, J.-P. Lepoittevin (Eds.), Contact Dermatitis, Springer, Heidelberg, 2011, pp. 793-817, https://doi.org/ 10.1007/978-3-642-03827-3 40.

[10] A.Y.L. Tang, ChK.Y. Lo, Chi-wai Kan, Textile dyes and human health: a systematic and citation network analysis review, Color, Technol. 134 (2018) 245-257, https://doi.org/10.1111/cote.12331.

[11] A. Gürses, M. Açıkyıldız, K. Güneș, M. Sadi Gürses, Dyes and Pigments. SpringerBriefs in Molecular Science, Springer, Cham, 2016, https://doi.org/ 10.1007/978-3-319-33892-7.

[12] D. Gadaleta, S. Manganelli, A. Manganaro, N. Porta, E. Benfenati, A knowledgebased expert rule system for predicting mutagenicity (Ames test) of aromatic amines and azo compounds, Toxicology 370 (2016) 20-30, https://doi.org/ 10.1016/j.tox.2016.09.008.

[13] B. Lellis, C.Z. Fávaro-Polonio, J. Alencar Pamphile, J.C. Polonio, Effects of textile dyes on health and the environment and bioremediation potential of living organisms, Biotechnol. Res. \& Innov. 3 (2019) 275-290, https://doi.org/10.1016/ j.biori.2019.09.001.

[14] D. Śmigiel-Kamińska, J. Pośpiech, J. Makowska, P. Stepnowski, J. Was-Gubała, J. Kumirska, The identification of polyester fibers dyed with disperse dyes for forensic purposes, Molecules 24 (3) (2019) 613, https://doi.org/10.3390/ molecules24030613.

[15] T. Kato, Y. Suzuki, M. Handa, Extraction and analysis of disperse dyes from colored polyester single fibers using liquid chromatography/linear ion trap tandem mass spectrometry, Anal. Sci. 32 (2016) 1019-1022, https://doi.org/10.2116/ analsci.32.1019.

[16] T.G. Schotman, X. Xiu, N. Rodewijk, J. van der Weerd, Application of dye analysis in forensic fibre and textile examination: case examples, Forensic Sci. Int. 278 (2017) 338-350, https://doi.org/10.1016/j.forsciint.2017.07.026.

[17] L.C. Abbott, S.N. Batchelor, J.R. Lindsay Smith, J.N. Moore, Resonance Raman and UV-visible spectroscopy of black dyes on textiles, Forensic Sci. Int. 202 (2010) 54-63, https://doi.org/10.1016/j.forsciint.2010.04.026.

[18] C. Hu, J. Zhu, H. Mei, H. Shi, H. Guo, G. Zhang, P. Wang, L. Lu, X. Zheng, A sensitive HPLC-MS/MS method for the analysis of fiber dyes, Forensic Chem 11 (2018) 1-6.

[19] Y. Zhou, Z. Du, Y. Zhang, Simultaneous determination of 17 disperse dyes in textile by ultra-high performance supercritical fluid chromatography combined with tandem mass spectrometry, Talanta 127 (2014) 108-115, https://doi.org/ 10.1016/j.talanta.2014.03.055.

[20] A. Carey, N. Rodewijk, X. Xu, J. van Der Weerd, Identification of dyes on single textile fibers by HPLC-DAD-MS, Anal. Chem. 85 (2013) 11335-11343, https://doi. org/10.1021/ac402173e.

[21] C. Sessa, R. Weiss, R. Niessner, N.P. Ivleva, H. Stege, Towards a Surface Enhanced Raman Scattering (SERS) spectra database for synthetic organic colourants in cultural heritage. The effect of using different metal substrates on the spectra, Microchem. J. 138 (2018) 209-225, https://doi.org/10.1016/j. microc.2018.01.009.

[22] S.Q. Lomax, J.F. Lomax, T.K. Graham, T.J.T. Moore, C.G. Knapp, Historical azo pigments: synthesis and characterization, J. Cult. Herit. 3 (2019) 218-224, https:// doi.org/10.1016/j.culher.2018.03.022.

[23] W. Fremout, S. Saverwyns, Identification of synthetic organic pigments: the role of a comprehensive digital Raman spectral library, J. Raman Spectrosc. 43 (2012) 1536-1544, https://doi.org/10.1002/jrs. 4054.

[24] M.M.J. Tecklenburg, D.J. Kosnak, A. Bhatnagar, D.K. Mohanty, Vibrational characterization of azobenzenes, azoxybenzenes and azoaromatic and azoxyaromatic polyethers, J. Raman Spectrosc. 28 (10) (1997) 755-763, https:// doi.org/10.1002/(SICI)1097-4555(199710)28:10<755::AID-JRS143>3.0.CO;2-V.

[25] P. Vandenabeele, L. Moens, H.G.M. Edwards, R. Dams, Raman spectroscopic database of azo pigments and application to modern art studies, J. Raman Spectrosc. 31 (2000) 509-517, https://doi.org/10.1002/1097-4555(200006)31: $6<509:$ :AID-JRS566>3.0.CO;2-0.

[26] A. Cesaratto, S.A. Centeno, J.R. Lombardi, N. Shibayama, M. Leona, A complete Raman study of common acid red dyes: application to the identification of artistic materials in polychrome prints, J. Raman Spectrosc. 48 (2017) 601-609, https:// doi.org/10.1002/jrs.5082.

[27] M.J. Pelletier, Quantitative analysis using Raman spectrometry, Appl. Spectrosc. 57 (2003) 20A-42A. https://www.osapublishing.org/as/abstract.cfm?URI=as $-57-1-20 \mathrm{~A}$.

[28] L. Lepot, K. De Wael, F. Gason, B. Gilbert, Application of Raman spectroscopy to forensic fibre cases, Sci. Justice 48 (2008) 109-117, https://doi.org/10.1016/j. scijus.2007.09.013.

[29] E. Smith, G. Dent, Modern Raman Spectroscopy: A Practical Approach, John Wiley \& Sons Ltd, Chichester, 2005, https://doi.org/10.1002/0470011831.

[30] N. Biswas, S. Umapathy, Structures, vibrational frequencies, and normal modes of substituted azo dyes: infrared, Raman and density functional calculations, J. Phys. Chem. 104 (2000) 2734-2745, https://doi.org/10.1021/jp9929263.

[31] A.J. Aller, Analytical Improvements in the vibrational spectroscopy for the study of biological systems, in: A. Hemantaranajan (Ed.), Advances in Plant Physiology, 1, Scientific Publishers, Jodhpur, 1998, pp. 441-477.

[32] F.J. Pereira, M.T. Díez, A.J. Aller, Effect of temperature on the crystallinity, size and fluorescent properties of zirconia-based nanoparticles, Mater. Chem. Phys. 152 (2015) 135-146, https://doi.org/10.1016/j.matchemphys.2014.12.025.

[33] M.I. Muñoz, A.J. Aller, D. Littlejohn, The bonding of heavy metals on nitric acidetched coal fly ashes functionalized with 2-mercaptoethanol or thioglycolic acid, Mater. Chem. Phys. 143 (2014) 1469-1480, https://doi.org/10.1016/j. matchemphys.2013.12.002.

[34] F.J. Pereira, M.D. Vazquez, L. Deban, A.J. Aller, Spectrometric characterisation of the solid complexes formed in the interaction of cysteine with As(III), Th(IV) and Zr(IV), Polyhedron 76 (2014) 71-80, https://doi.org/10.1016/j.poly.2014.03.036.

[35] F.J. Pereira, M.T. Díez, A.J. Aller, Synthesis and characterization of arsenic-doped cysteine-capped thoria-based nanoparticles, J. Nanopart. Research 15 (2013) 1895, https://doi.org/10.1007/s11051-013-1895-8. 